\title{
Apical Extrusion of Debris During Root Canal Prepa- ration with Different Brands of ProTaper System
}

\author{
Heshmatallah Shahraki Ebrahimi ${ }^{1}$, Amin Motameni Tabatabaie ${ }^{1}$, \\ Saeed Bakhshi Moqaddam Firouz Abad ${ }^{1 *}$, Yasaman Fereydonnia ${ }^{2}$ \\ ${ }^{1}$ Endodontics Dept, School of Dentistry, Zahedan University of Medical Sciences, Iran \\ ${ }^{2}$ Private Practice, Tehran, Iran
}

\begin{tabular}{l} 
ARTICLE INFO \\
\hline Article History \\
Received:June 2021 \\
Accepted: August 2021 \\
ePublished: Oct 2021 \\
\hline Corresponding author \\
Saeed Bakhshi Moqaddam \\
Firouz Abad,Endodontics \\
Dept, School of Dentistry, \\
Zahedan University of \\
Medical Sciences, Iran \\
Email: saeedbm1234@ \\
gmail.com
\end{tabular}

Introduction

Cleaning and shaping of the root canal system is an important step performed by using mechanical instruments and irrigating solutions. Complete debridement of the root canal in the process of root canal preparation is imperative for a successful endodontic treatment. ${ }^{(1-3)}$ Reduction of the amount of extruded apical debris should be among the main goals of root canal preparation to prevent postoperative flare-ups. This can be done by correct selection of root canal preparation technique and instruments. ${ }^{(4)}$ Thus, the technique with minimal extrusion of debris would be more favorable. ${ }^{(5)}$

\begin{abstract}
Background and Aim: Complete debridement of the root canal system is impera-
exthe determined by a $\# 10 \mathrm{~K}$-file. The teeth were mounted in an experimental setup as explained by Myers and Montgomery, and were randomized into 4 groups $(n=20)$ for root canal instrumentation with ProTaper Universal (PTU), Dia-PT file (DPT), PathMax Pro (PMP), and hand files. The root canals were irrigated with double distilled water after using two files. After preparation, the debris collecting tubes were separated from the setup. Debris adhering to root surface was also collected by rinsing the canals with $1 \mathrm{~mL}$ of double distilled water. The tubes were incubated at $70^{\circ} \mathrm{C}$ for 5 days. Dried debris was weighed and subtracted from the weight

Results: The extruded debris in PTU group was significantly higher than that in Proups $(\mathrm{P}<0.05)$. The extruded debris in DPT group was signifiin hand file group was significantly higher than that in DPT and PMP groups $(\mathrm{P}<0.05)$. The extruded debris in PMP group was significantly lower than that in PTU and hand file groups.

Conclusion: PTU caused maximum and PMP caused minimum extrusion of debris.

Keywords: Root canal Therapy; Smear Layer; Root Canal Preparation
\end{abstract}

\section{J Res Dent Maxillofac Sci 2021;6(4):18-22.}

Root canal preparation is performed by using hand and rotary instruments. ${ }^{(6,7)}$ Several instruments and techniques have been proposed for root canal preparation, each having advantages and disadvantages. Thus, it is important to find the most efficient technique and instruments to maximize the treatment success. ${ }^{(8,9)}$ Different reports are available regarding the extrusion of debris in the process of root canal preparation with different rotary systems, showing that root canal preparation by rotary systems decreases the apical extrusion of debris ${ }^{(10,11)}$

Several rotary systems with different designs are extensively used for root canal treatments. ${ }^{(12)}$ 
In use of rotary instruments, debris is entrapped in the flutes; thus, accumulation of debris in the root canal system is prevented. The rotary instruments guide the debris towards the canal orifice .$^{(12)}$ However, rotary systems can also cause apical extrusion of debris. ${ }^{(4,13)}$

Some differences exist in the amount of extrusion of debris among different rotary systems due to differences in the technique used, cutting blade design, cross-sectional design, degree of taper, flexibility, type of alloy, number of files used, type of movement, and cutting efficiency. ${ }^{(13)}$

ProTaper system is a commonly used rotary system for endodontic treatment. It is available in different commercial brands. This system has decreased the contact of file and dentin due to its triangular and convex cross-sectional design; this particular design prevents excessive removal of dentin and weakening of root canal walls..$^{(14,15)}$

The standard set of ProTaper Universal (PTU; Dentsply) has three files for coronal shaping and three files for apical preparation (finishing). ProTaper system is a suitable alternative for files with fixed taper. The tip of small-size shaping ProTaper files is used as a guide to passively determine the canal path, which was used to be done with hand files.

Dia-PT file (DPT; Dia-Dent) is a commercially available brand of ProTaper rotary files with a triangular and convex cross-section. According to the manufacturer, this file operates at 250-350 $\mathrm{rpm}$ and 2-3 N/cm torque. One size (Dx to D5) and assorted (D1 to D4) packs are available in 21 and $25 \mathrm{~mm}$ lengths.

PathMax Pro file (PMP) is fabricated from the novel heat-treated nickel-titanium alloy and is used for shaping of the root canal system. PMP files are optimized to have higher cutting efficiency while removing lower amounts of dentin from the root canal walls. The resistance of these files against cyclic fatigue is twice that of ProTaper Gold and 6 times that of PTU.

Considering the limited number of studies on the extrusion of debris by using different commercial brands of ProTaper system, this study aimed to compare the apical extrusion of debris following the use of different brands of ProTaper system.

\section{Materials and Methods}

This in vitro, experimental study was conducted on 80 extracted mandibular molars. The study was approved by the ethics committee of Zahedan University of Medical Sciences (IR. ZAUMS.REC.1396.340). The teeth were extracted for purposes not related to this study, and the patients consented to the use of their extracted teeth for this study. The teeth were clinically and radiographically inspected. The mesial root of mandibular molars with two orifices, two canals, and two separate apical foramina with mesiobuccal canal curvature $<10$ degrees according to the Schneider's classification were included. Also, all teeth had mature apices and had not undergone endodontic treatment. They all had apical size \#15. The root surfaces were cleaned by a scaler, carious lesions and restorations were removed, and an access cavity was prepared using a round bur (\#1014; KG Sorensen, Barueri, SP, Brazil) with high-speed hand-piece under air and water spray.

The working length of the mesial root was determined by observing the tip of the file at the apical foramen and subtracting $0.5 \mathrm{~mm}$ from this length. The primary apical diameter matched that of a \#10 K-file. The tubes used for debris collection were first weighed and their weight was recorded. The teeth were mounted in an experimental setup as explained by Myers and Montgomery. ${ }^{(16)}$ The teeth were then randomized into 4 groups $(n=20)$ for preparation with PTU (Dentsply Maillefer, Ballaigues, Switzerland), DPT (Dia-Dent, Cheongwon, Korea), and PMP (Pro, Nikinc Dental B.V. Netherlands) according to the manufacturer's instructions, and hand K-files (Mani, Inc., Utsunomiya Tochigi, Japan) with the crown-down technique. The root canals were irrigated with double distilled water after using two files. After root canal preparation, the tubes were separated from the setup. The debris attached to the root canal wall was also collected by rinsing the canals with $1 \mathrm{~mL}$ of double distilled water and collecting it. The tubes were then incubated at $70^{\circ} \mathrm{C}$ for 5 days to dry the debris. The weight of empty tubes was then subtracted from the weight of tubes containing dry debris. 
Data were analyzed using SPSS version 20 via the Kolmogorov-Smirnov test, Levene's test, one-way ANOVA and LSD test (for pairwisecomparisons) at 0.05 level of significance.

\section{Results}

Table 1 presents the measures of central dispersion for the amount of extruded debris in the four groups. As shown, PTU caused maximum and PMP caused minimum extrusion of debris. The Kolmogorov-Smirnov test showed normal distribution of data regarding the amount of extruded debris in the four groups $(\mathrm{P}>0.05)$. The Levene's test also showed homogeneity of variances $(\mathrm{P}>0.05)$. Thus, the four groups were compared in this regard using one-way ANOVA.

Table 1. Measures of central dispersion for the amount of extruded debris in the four groups $(\mathbf{n}=\mathbf{2 0})$

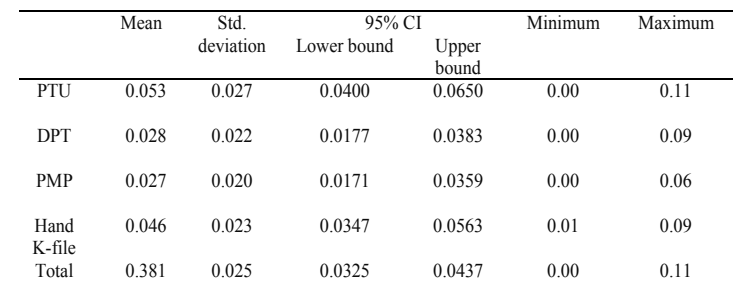

PTU: ProTaper Universal; DPT: Dia-PT file; PMP: PathMax Pro

The results showed a significant difference in this regard among the four groups $(\mathrm{P}=0.001$, Table 2).

Table 2.Results of one-way ANOVA regarding the amount of extruded debris

\begin{tabular}{cccccc}
\hline Variable & $\begin{array}{c}\text { Sum of } \\
\text { squares }\end{array}$ & $\begin{array}{c}\text { Degree of } \\
\text { freedom }\end{array}$ & $\begin{array}{c}\text { Mean } \\
\text { square }\end{array}$ & $\mathrm{F}$ & $\mathrm{P}$ \\
\hline $\begin{array}{c}\text { Between- } \\
\text { group }\end{array}$ & 0.010 & 3 & 0.003 & 6.247 & 0.001 \\
$\begin{array}{c}\text { Within- } \\
\text { group } \\
\text { Total }\end{array}$ & 0.040 & 76 & 0.001 & & \\
\hline
\end{tabular}

Thus, pairwise comparisons were performed using the LSD test (Table 3). As shown, the extruded debris in the PTU group was significantly higher than that in the DPT and PMP groups $(\mathrm{P}<0.05)$. The extruded debris in the DPT group was significantly lower than that in the PTU and hand file groups $(\mathrm{P}<0.05)$. The extruded debris in the hand file group was significantly higher than that in the DPT and PMP groups $(\mathrm{P}<0.05)$. The extruded debris in the PMP group was significantly lower than that in the PTU and hand file groups.

Table 3. Pairwise comparison of the groups regarding the amount of extruded debris with LSD test

\begin{tabular}{ccc}
\hline & Groups & P value \\
\hline \multirow{2}{*}{ PTU } & DPT & 0.001 \\
& PMP & 0.001 \\
& Hand K-file & 0.34 \\
DPT & PMP & 0.83 \\
& Hand K-file & 0.01 \\
PMP & Hand K-file & 0.011 \\
\hline
\end{tabular}

\section{Discussion}

Decreased extrusion of debris is a major advantage of rotary systems compared with hand files. ${ }^{(12)}$ This study compared apical extrusion of debris following the use of different brands of ProTaper system. The results showed that the extruded debris in the PTU group was significantly higher than that in the DPT and PMP groups $(\mathrm{P}<0.05)$. The extruded debris in the DPT group was significantly lower than that in the PTU and hand file groups $(\mathrm{P}<0.05)$. The extruded debris in the hand file group was significantly higher than that in the DPT and PMP groups $(\mathrm{P}<0.05)$. The extruded debris in the PMP group was significantly lower than that in the PTU and hand file groups. PTU caused maximum and PMP caused minimum extrusion of debris.

Cakici et al, ${ }^{(2)}$ in 2016 evaluated the amount of extruded debris during root canal preparation by ProTaper Gold (Dentsply), PTU (Dentsply), ProTaper Next (Dentsply), and Reciproc, and showed that all systems caused apical extrusion of debris although ProTaper Gold, ProTaper Next, and Reciproc caused lower debris extrusion than PTU. Although they compared three types of ProTaper files from the same commercial brand (Dentsply) with Reciproc, which has a different motion, their results regarding PTU were in agreement 
with current findings, reporting maximum extrusion of debris in use of PTU compared with other files. Considering the similar methodology of the present study and that of Cakici et al, ${ }^{(2)}$ it may be concluded that PTU causes greater extrusion of debris..$^{(2)}$ Surakanti et al, ${ }^{(14)}$ in 2014 compared apical extrusion of debris in root canal preparation with HyFlex, PTU and WaveOne in 60 mandibular first premolars randomized into three groups, and showed that WaveOne and PTU caused greater debris extrusion than HyFlex. Different alloy type, type of movement, and lower taper of HyFlex compared with WaveOne may explain lower extrusion of debris in HyFlex system. However, since both HyFlex and PTU have the same type of movement, and the taper of the final file is the same in both systems, high extrusion of debris in use of PTU may be attributed to its geometry. ${ }^{(14)}$ Koçak et al, ${ }^{(17)}$ in 2014 compared apical extrusion of debris by PTU and ProTaper Next and reported greater debris extrusion in use of PTU, which was in agreement with the present findings. Capar et al, ${ }^{(18)}$ in 2014 evaluated the apical extrusion of debris following the use of Twisted File Adaptive, ProTaper Next, PTU, and HyFlex in 60 extracted mandibular premolars in four groups and found that the extruded debris in ProTaper Next and Twisted File Adaptive was lower than that in PTU and HyFlex. Hussein et al, ${ }^{(4)}$ in 2014 evaluated apical extrusion of debris and showed that the amount of extruded debris in use of full-rotation rotary and hand files was lower than that in use of reciprocating systems, and Mtwo caused minimum extrusion of debris. They attributed the lower extrusion of debris in Mtwo, compared with PTU, to the geometrical shape of PTU (cross-sectional design, and deeper and larger flutes). Their results were in line with the present findings. Also, they found no significant difference between PTU and hand files in extrusion of debris, which was similar to the current results. Mittal et al, ${ }^{(16)}$ in 2015 compared apical extrusion of bacteria after root canal preparation with hand files, and ProTaper and One-Shape rotary systems. They evaluated 42 mandibular premolars inoculated with Enterococcus faecalis in three groups of 12 and a control group of 6 . The root canals were prepared with hand files, ProTaper and One-Shape. They showed that all systems caused apical extrusion of bacteria. Apical extrusion of bacteria was maximum in hand file and lower in ProTaper and One-Shape rotary systems. Silva et al, ${ }^{(19)}$ in 2014 evaluated the apical extrusion of debris by reciprocating and rotational systems using Reciproc, WaveOne, and PTU systems. They showed that PTU caused significantly greater extrusion of debris compared with Reciproc and WaveOne.

Significant differences in the amount of extruded debris can be due to the manufacturing process and particularly type of alloy used in DPT and PMP files, which are clearly different especially in PMP files. Accidental uncontrolled movements during root canal preparation and over-instrumentation can also explain the similar results of using hand files and PTU in this respect.

\section{Conclusion}

Since PTU showed maximum apical extrusion of debris in this study, alternative files with the same design should be preferred for use especially in necrotic teeth or those requiring endodontic retreatment.

\section{References}

1.Mudita Verma, N, Meena R, Kumari A, Sudhanva Mallandur R, Vikram Gowda V. Comparison of apical debris extrusion during root canal preparation using instrumentation techniques with two operating principles: An in vitro study. J Conserv Dent 2017;20(2): 96-9.

2.Cakici F, Cakici EB, Küçükekenci FF, Uygun AD, Arslan H. Apically extruded debris during root canal preparation using ProTaper Gold, ProTaper Universal, ProTaper Next, and RECIPROC instruments. Int J Artif Organs 2016;39(3):128-31.

3.Hussein M, Al-Zaka M. Quantitative evaluation of the amount of apically extruded debris using 3 different rotary instrumentation systems. Oral Surg Oral Med Oral Pathol Oral Radiol. 2014;11(1):1-9.

4.Radeva EN, Vassileva RI. Comparative Study of Apically Extruded Debris and Irrigant After using two Rotary Systems (K3, RaCe). J. IMAB - Annu. Proceeding (Sci. Pap.) 2014;20(1):459-63.

5.Adl A, Sahebi S, Moazami F, Niknam M, Comparison of apical debris extrusion using a conventional and two rotary techniques. Int Endod J 2009;4(4):135-8.

6.American Dental Association Council on Dental Materials Instruments and Equipment: Revised ADA specification No. 28 for endodontics files and reamers, J Am Dent Assoc 1982;104:506.

7.Young GR, Parashos P, Messer HH. The principles of techniques for cleaning root canals. Aust Dent J. 2007 Mar;52:S52-63. 
8.Rowan MB, Nicholls JI, Steiner J. Torsional properties of stainless steel and nickel-titanium endodontic files, J Endod 1996;22:341.

9.Kustarci A, Akpinar KE, Sumer Z, Er K, Bek B. Apical extrusion of intracanal bacteria following use of various instrumentation techniques. Int Endod J 2008;41(12):106671.

10. Tanalp J, Kaptan F, Sert S, Kayahan B, Bayirl G. Quantitative evaluation of the amount of apically extruded debris using 3 different rotary instrumentation systems. Oral Surg Oral Med Oral Pathol Oral Radiol Endod. 2006;101(2):2507.

11. Leonardi LE, Atlas DM, Raiden G. Apical extrusion of debris by manual and mechanical instrumentation. Braz Dent J 2007;18(1):16-9.

12. Pinky K, Arathi R, Ethel S, Ramya S, BaranyaShrikrishna S. Evaluation of conventional, protaper hand and protaper rotary instrumentation system for apical extrusion of debris, irrigants and bacteria- An in vitro randomized trial. J. clin. exp. dent. 2017 Feb;9(2):e254.

13. Luisi SB, Zottis AC, Piffer CS, Vanzin AC, Ligabue RA. Apical extrusion of debris after hand, engine-driven reciprocating and continuous preparation. Revista Odonto Ciência 2010;25(3):288-91.

14. Surakanti JR, Venkata RC, Vemisetty HK, Dandolu RK, Jaya NK, Thota S. Comparative evaluation of apically extruded debris during root canal preparation using ProTaper $^{\mathrm{TM}}$, Hyflex ${ }^{\mathrm{TM}}$ and Waveone ${ }^{\mathrm{TM}}$ rotary systems. J Conserv Dent. 2014 Mar;17(2):129.

15. Torabinejad M, Walton R. Endodontics 4th Edition Principles and Practice, March 2008, P:496.

16. Mittal R, Singla MG, Garg A, Dhawan A. A comparison of apical bacterial extrusion in manual, ProTaper rotary, and One Shape rotary instrumentation techniques. J Endod 2015;41(12):2040-4.

17. Kocak M, Cicek E, Kocak S, Saglam B, Yilmaz N. Apical extrusion of debris using ProTaper Universal and ProTaper Next rotary systems. Int Endod J 2015 Mar;48(3):283-6. 18. Capar ID, Hakan A, Akcay M, Ertas H. An in vitro comparison of apically extruded debris and instrumentation times with ProTaper Universal, ProTaper Next, Twisted File Adaptive, and Hyflex instruments. J Endod 2014;40(10):1638-41.

19. Silva EJ, Sa L, Belladonna FG, Neves AA, AccorsiMendonca T, Vieira VT, et al. Reciprocating versus rotary systems for root filling removal: assessment of the apically extruded material. J Endod 2014;40(12): 2077-80.

Cite this paper as: Shahraki ebrahimi $\mathrm{H}$, Motameni Tabatabaie A, Bakhshi Moqaddam Firouz Abad S, Fereydonnia Y. Apical Extrusion of Debris During Root Canal Preparation With Different Brands of ProTaper System. J Res Dent Maxillofac Sci. 2021;6(4) :18-22 